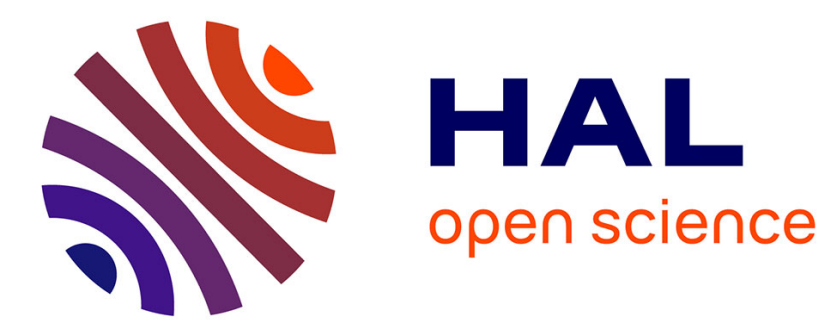

\title{
Is phylogeography helpful for invasive species risk assessment? The case study of the bark beetle genus Dendroctonus
}

\author{
Martin Godefroid, Jean Yves Rasplus, Jean-Pierre Rossi
}

\section{To cite this version:}

Martin Godefroid, Jean Yves Rasplus, Jean-Pierre Rossi. Is phylogeography helpful for invasive species risk assessment? The case study of the bark beetle genus Dendroctonus. Ecography, 2016, 39 (12), pp.1197-1209. 10.1111/ecog.01474 . hal-01602591

\section{HAL Id: hal-01602591 \\ https://hal.science/hal-01602591}

Submitted on 28 May 2021

HAL is a multi-disciplinary open access archive for the deposit and dissemination of scientific research documents, whether they are published or not. The documents may come from teaching and research institutions in France or abroad, or from public or private research centers.
L'archive ouverte pluridisciplinaire HAL, est destinée au dépôt et à la diffusion de documents scientifiques de niveau recherche, publiés ou non, émanant des établissements d'enseignement et de recherche français ou étrangers, des laboratoires publics ou privés. 


\title{
Is phylogeography helpful for invasive species risk assessment? The case study of the bark beetle genus Dendroctonus
}

\author{
Martin Godefroid, Jean-Yves Rasplus and Jean-Pierre Rossi \\ M. Godefroid (martin.godefroid@gmail.com), J.-Y. Rasplus and J.-P. Rossi, INRA, UMR1062 CBGP (Centre de Biologie pour la Gestion des \\ Populations) - Avenue du Campus Agropolis, Montferrier sur Lez, CS30016, FR-34988, France.
}

\begin{abstract}
Despite evidence that conspecific lineages may display different climatic tolerances, most invasion risk assessment tools are calibrated without considering phylogeographic information. This study aims to investigate the existence of intraspecific niche divergence within a group of insect pests and to explore how the inclusion of phylogeographic information into species distribution models may alter the estimation of the potential distribution of a species. We studied North American bark beetles belonging to the genus Dendroctonus, a group of pests of conifers that are listed as quarantine species in numerous countries. Most Dendroctonus species exhibit strong genetic divergence that appears to be geographically structured and shaped by historical events and biotic factors. We modeled all lineage distributions within five species, using MaxEnt and Boosted Regression Trees, and compared the results with the models fitted at the species scale. Multivariate analysis and niche similarity and equivalency tests were additionally performed to investigate the existence and magnitude of climatic niche divergence between conspecific lineages. We also tested the ability of lineage-based models to predict the region invaded by $D$. valens in China. Conspecific lineages showed a climatic niche more similar than expected by chance, but displayed different climatic envelopes in their native range and, consequently, different estimates of potential distributions. We also observed that classical models calibrated using the entire range of the species could potentially under-or overestimate the potential range of the species when compared to a global prediction built by aggregating lineage-based projections. This study showed that the invasive phylogeographic lineage of $D$. valens has invaded regions characterized by climatic conditions highly similar to those encountered in its native range suggesting that preadaptations to environment might have played a role in this invasion. This study highlights how our perception of the invasion risk of pests may be altered when integrating phylogeographic information.
\end{abstract}

Most species exhibit phylogeographic structure in the form of discrete genetic units within their distribution range. Considerable attention has been paid to describe these patterns and to identify the underlying processes that may involve historical events, dispersal limits, geographic barriers, biotic interactions or ecological niche evolution (Avise et al. 1987, Marske et al. 2013). Because they share a recent common ancestor, conspecific lineages often display similar climatic tolerances (Peterson et al. 1999, Martínez-Meyer et al. 2004, Kozak and Wiens 2006, Peterson 2011, Araújo et al. 2013). However, in some cases, the observed intraspecific genetic differentiation is associated to adaptations to local environments with subsequent divergence of the fundamental niche sensu Hutchinson (1957) (Rehfeldt et al. 1999, Michalak et al. 2001, Grout and Stoltz 2007). Understanding how phylogeographic structures correspond to different climatic tolerances has consequently received increasing attention especially in the context of invasion biology and climate change (Lachmuth et al. 2010, Pearman et al. 2010, Thompson et al. 2011, Rey et al. 2012, Schulte et al. 2012, D'Amen et al. 2013, Guisan et al. 2014, Godefroid et al. 2015, Strubbe et al. 2015).
When intraspecific lineages differ in terms of climatic tolerances, their invasion capacity in a given habitat may differ. Consequently, these lineages address contrasted biosecurity threats to areas they may invade hence deserving different management plans. As underlined by Peterson and Holt (2003), integrating phylogeographic information into pest risk assessment allows to limit the overestimation of invasion risk when only a population subset finds suitable conditions in a considered area. For example, Rey et al. (2012) showed how populations of the ant Wasmannia auropunctata located at the southern limit of its native area, were pre-adapted to the cold conditions found in an invaded area (Israel). Similarly, Lachmuth et al. (2010) showed that different intraspecific units within the South African ragwort Senecio inaequidens displayed contrasted invasiveness in northern Europe because they exhibit different climatic preferences. However, relatively little attention has been paid to explore how considering within-species variation of the realized niche sensu Hutchinson (1957) could valuably improve risk assessment of invasive species (Peterson and Holt 2003) although more information is available regarding conservation planning (Rissler et al. 2006, Pearman et al. 2010, 
Benito Garzón et al. 2011, D’Amen et al. 2013, Fitzpatrick and Keller 2014).

Estimating the full extent of environmental damages caused by invasive species has proved to be a difficult task but most estimates indicate that the costs associated to prevention and control must be extremely high (Pimentel et al. 2001, 2005). A current debate concerns the better costeffectiveness of investments in prevention over investments in control although the social consequences of such a strategy may result in a greater probability of future invasions and lower social welfare (Finnoff et al. 2007). Prevention largely relies on pest risk analysis (PRA; Devorshak 2012) that consider various aspects of the biology and ecology of species and include species distribution models (SDMs) as tools to assess their potential geographical distributions. In PRA, SDMs are generally based on climate data and are usually fitted with no consideration of the phylogeographic structure of the considered species. Consequently, most predictions assume that species are homogeneous entities and that intraspecific variation in climatic tolerances is weak. However, contrasted environmental tolerances have been shown either between populations inside species native range (Grout and Stoltz 2007, Rey et al. 2012) or between native and invasive populations (Broennimann et al. 2007, Hill et al. 2013) suggesting that climatic niche preferences may evolve over reduced evolutionary timescales i.e. those involved in biological invasions. Nevertheless, this point is currently a matter of debate (Peterson 2011, Petitpierre et al. 2012, Strubbe et al. 2013) since discrepancies in the realized niche may be explained by true changes in the fundamental niche as well as changes in the patterns of fundamental niche occupancy due to biotic interactions or dispersal constraints (Araújo and Peterson 2012).

The present study considers the impact of accounting for phylogeographic structures in the outputs of SDMs in the framework of PRA. How our estimate of the invasion risk associated to a species is changed when considering the realized climatic niche of the phylogeographic lineages separately rather than the species as a whole? To do so, we retained the bark beetle genus Dendroctonus as our biological model (see Methods). It comprises several species that are serious pests of conifer forests (Wood 1982, Six and Bracewell 2015) and many species are listed as quarantine species in numerous temperate countries of the world including European Union. We combined phylogeographic data and SDMs to specifically address the following questions: 1) do conspecific lineages of several Dendroctonus species exhibit differences in their realized climatic niche? 2) To which extent accounting for species phylogeography in SDM alter our perception of the risk of biological invasion? 3) How the realized climatic niche of $D$. valens has been conserved during its invasion of Chinese forests? Which role has played the phylogeographic structure of D. valens during its invasion of China?

\section{Methods}

The genus Dendroctonus (Coleoptera: Curculionidae: Scolytinae) comprises 19 species, 17 of which are native to Central and North America, where they are considered important pests of conifers (Pinus, Picea, Pseudotsuga and Larix; Wood 1982, Six and Bracewell 2015). Particular attention has been paid to some of these bark beetles because of the severe damage they cause in their native range as well as in recently colonized areas. The mountain pine beetle $D$. ponderosae produces severe outbreaks in the northern part of its range, devastating million hectares of forest in British Columbia and Alberta (Canada) and constitutes a serious threat to the boreal forests (Cullingham et al. 2011). The red turpentine beetle $D$. valens was recently introduced in China, causing high mortality to a major reforestation species, Pinus tabuliformis (Yan et al. 2005, Sun et al. 2013). Given their capacity to kill trees, Dendroctonus species are frequently listed as quarantine species in numerous countries (i.e. Australia, China, European Union, New Zealand, etc.). For these species, intraspecific genetic divergence, shaped by a combination of past geologic events and glacial-interglacial cycles during the Pleistocene (Hewitt 1996), exhibits a marked geographical structure at the continental scale (Kelley et al. 1999, Maroja et al. 2007, Mock et al. 2007, Anducho-reyes et al. 2008, Cai et al. 2008, Ruiz et al. 2010, Sánchez-Sánchez et al. 2012). Consequently, the genus Dendroctonus is an ideal model to assess how the incorporation of the phylogeographic structure of pests affects risk assessment. In addition, the origin of the invasion of $D$. valens has been elucidated (Cognato et al. 2005, Cai et al. 2008) and consequently provides an interesting case to investigate the similarity of climates in invaded and native regions.

\section{Species and occurrence data}

We investigated the realized climatic niche of intraspecific lineages within five species of Dendroctonus that exhibited strong phylogeographic structures and for which a large number of occurrence records were available (Table 1, Supplementary material Appendix 1, Fig. A1). These species included the red turpentine beetle Dendroctonus valens, the mountain pine beetle $D$. ponderosae, the spruce beetle $D$. rufipennis, the Douglas fir beetle D. pseudotsugae and the western pine beetle $D$. brevicomis. Conspecific lineages of $D$. valens and $D$. brevicomis exhibit the strongest levels of genetic differentiation, similar to that observed between recognized Dendroctonus species, and thus should probably be considered a species complexes (Kelley et al. 1999, Cai et al. 2008). Low levels of genetic differentiation occur among conspecific lineages of $D$. rufipennis and $D$. pseudotsugae, suggesting a more recent divergence within species (i.e. estimated divergence times ranging from 1 to 2 million yr ago; Maroja et al. 2007, Ruiz et al. 2010). Finally, the intraspecific genetic divergence within $D$. ponderosae appears relatively low, suggesting that these lineages have recently diverged (Mock et al. 2007, Cullingham et al. 2012). We collected occurrence data from the literature (Wood 1982) and online databases (e.g. GBIF < http://data.gbif.org > or the T. H. Atkinson personal website on bark and ambrosia beetles <http://www.barkbeetles.info/>). We georeferenced using Google Earth most of the occurrence records obtained in literature (records with too 'imprecise' locality name were removed from the dataset to avoid using erroneously georeferenced records in the study). We also checked 
Table 1. Bark beetles belonging to the Dendroctonus genus selected in this study to address intraspecific niche divergence at a continentscale. We name the lineages by using their taxonomic names (in case of recognized subspecies), their geographic ranges or their main host' name. We indicate the number of occurrences used for species distribution modeling as well as the references of the published phylogeographic studies.

\begin{tabular}{|c|c|c|c|c|c|}
\hline Species & Intra-specific lineage & Geographic range & Symbol & $\begin{array}{l}\text { Records } \\
\text { number }\end{array}$ & $\begin{array}{l}\text { Phylogeography } \\
\text { reference }\end{array}$ \\
\hline \multirow[t]{4}{*}{ Dendroctonus valens } & all lineages & Canada, USA and Mexico & Dvall & 747 & Cai et al. 2008 \\
\hline & D. valens eastern lineage & Northeastern USA & Dveas & 356 & \\
\hline & $D$. valens western lineage & $\begin{array}{l}\text { Western USA and southern } \\
\text { Canada }\end{array}$ & Dvwes & 289 & \\
\hline & D. valens southern lineage & Mexico and Central America & Dvmex & 102 & \\
\hline \multirow[t]{3}{*}{ Dendroctonus ponderosae } & all lineages & Canada, USA and Mexico & Dpall & 226 & Mock et al. 2007 \\
\hline & D. ponderosae lineage monticolae & Southern Rocky montains & Dpmon & 79 & \\
\hline & $D$. ponderosae lineage ponderosae & Western USA and Canada & Dppon & 147 & \\
\hline \multirow[t]{3}{*}{ Dendroctonus rufipennis } & all lineages & Canada and USA & Drall & 224 & Maroja et al. 2007 \\
\hline & D. rufipennis (Picea engelmannii) & Rocky Mountains & Drroc & 122 & \\
\hline & D. rufipennis (Picea glauca) & $\begin{array}{l}\text { Canada and Rocky } \\
\text { Mountains }\end{array}$ & Drcan & 102 & \\
\hline \multirow[t]{3}{*}{ Dendroctonus brevicomis } & all lineages & Canada, USA and Mexico & & 229 & Kelley et al. 1999 \\
\hline & $\begin{array}{l}\text { D. brevicomis (Pinus ponderosa } \\
\text { ponderosa) }\end{array}$ & $\begin{array}{l}\text { Western USA (Pacific coast) } \\
\text { and southern Canada } \\
\text { (British Columbia) }\end{array}$ & Dbnor & 145 & \\
\hline & $\begin{array}{l}\text { D. brevicomis (Pinus ponderosa } \\
\text { scopulorum) }\end{array}$ & $\begin{array}{l}\text { Southern Rocky Mountains } \\
\text { and Mexico }\end{array}$ & Dbsou & 84 & \\
\hline \multirow{3}{*}{$\begin{array}{l}\text { Dendroctonus } \\
\text { pseudotsugae }\end{array}$} & all lineages & Canada, USA and Mexico & Dpsall & 217 & Ruiz et al. 2010 \\
\hline & D. pseudotsugae pseudotsugae & USA and southern Canada & Dppse & 202 & \\
\hline & D. pseudotsugae barragani & Mexico & Dpbar & 15 & \\
\hline
\end{tabular}

with Google Earth the geographic coordinates of already georeferenced records (obviously erroneous records were also removed from our dataset). Each occurrence was assigned to a particular lineage, depending on the published phylogeography (Table 1, Supplementary material Appendix 1, Fig. A1). Globally, phylogeographic structures of most species were well resolved and most lineages occurred in relatively well-delimited geographic areas. This allowed us to confidently assign occurrences to lineages. Dendroctonus ponderosae exhibited a clear isolation by distance around the Great Basin desert (Mock et al. 2007) and an on-going process of reproductive isolation between western (California, Oregon) and eastern (Utah, Idaho) populations, on both sides of this desert (Bracewell et al. 2011). We used this intraspecific split to assign occurrences to lineages (Supplementary material Appendix 1, Fig. A1b). Differentiation between these two entities is confirmed by the fact that $D$. ponderosae was originally described as two entities by Hopkins (1909) based on morphology: $D$. monticolae corresponding to eastern populations and $D$. ponderosae including western and northern populations (Canada). These two entities were later synonymized to $D$. ponderosae by Wood (1963).

The distributions of two phylogeographic lineages of $D$. valens overlap in Mexico (Cai et al. 2008). Consequently, several occurrences were assigned to multiple lineages. We assigned all occurrences of $D$. valens from Mexico and Central America to the southern lineage, whereas we assigned occurrences from the Sierra Madre Occidental (SMOC, Mexico) and from all western America to the western lineage (Supplementary material Appendix 1, Fig A1a). We excluded two records of $D$. valens (Fort Chipewyan, Alberta, Canada and Fort Smith, Northwest Territories, Canada) found in Wood (1982) because they were sampled far away from the sampling area investigated by Cai et al. (2008). Similarly, we did not include D. rufipennis specimens feeding on Picea sitchensis along the western coast of America, since this area was not sampled by Maroja et al. (2007).

\section{Bioclimatic data}

Intraspecific climatic envelope divergence was investigated using a set of 19 bioclimatic variables available from the Worldclim database (Hijmans et al. 2005) at a resolution of 2.5 minutes (Table 2). We define here the climatic envelope of a lineage as the multidimensional object defined

Table 2. Bioclimatic variables used to investigate the climatic niche of Dendroctonus species and lineages.

\begin{tabular}{lc}
\hline Bioclimatic variables & Symbol \\
\hline Annual mean temperature & $\mathrm{BIO} 1$ \\
Mean diurnal range & $\mathrm{BIO} 2$ \\
Isothermality & $\mathrm{BIO} 3$ \\
Temperature seasonality & $\mathrm{BIO} 4$ \\
Maximum temperature of warmest month & $\mathrm{BIO5}$ \\
Minimum temperature of coldest month & $\mathrm{BIO6}$ \\
Temperature annual range & $\mathrm{BIO} 7$ \\
Mean temperature of wettest quarter & $\mathrm{BIO} 8$ \\
Mean temperature of driest quarter & $\mathrm{BIO} 9$ \\
Mean temperature of warmest quarter & $\mathrm{BIO} 10$ \\
Mean temperature of coldest quarter & $\mathrm{BIO} 11$ \\
Annual precipitation & $\mathrm{BIO} 12$ \\
Precipitation of wettest month & $\mathrm{BIO} 13$ \\
Precipitation of driest month & $\mathrm{BIO} 14$ \\
Precipitation seasonality & $\mathrm{BIO} 15$ \\
Precipitation of wettest quarter & $\mathrm{BIO} 16$ \\
Precipitation of driest quarter & $\mathrm{BIO} 17$ \\
Precipitation of warmest quarter & $\mathrm{BIO} 18$ \\
Precipitation of coldest quarter & $\mathrm{BIO} 19$ \\
\hline
\end{tabular}


by the presence of this lineage in the climatic space. These data were derived from monthly temperatures and annual rainfall trends between 1950-2000. All variables were considered when performing multivariate analysis (see below), whereas a reduced climatic dataset was used to fit SDMs. The choice of environmental descriptors is known to strongly affect SDMs performance when extrapolating in space or time (Peterson and Nakazawa 2008, Rödder and Lötters 2009). The best environmental dataset to assess invasion risk includes proximal, ecologically relevant and non-highly correlated variables (Elith and Leathwick 2009, Jiménez-Valverde et al. 2011, Dormann et al. 2013). Consequently, we fitted our models using temperature and rainfall extremes that are likely to convey conditions of physiological stress for bark beetles (Wood 1982, Ungerer et al. 1999). We avoided using highly correlated climatic descriptors (Pearson's correlation index $<0.7$; Dormann et al. 2013). Despite evidence suggesting that temperature seasonality is critical for some mass-attacking Dendroctonus species (Logan and Bentz 1999), we did not include these descriptors (e.g. bio2, bio3, bio4, and bio7 in Table 2) in models because they are highly correlated with temperature extremes in native and projected areas. Following Jiménez-Valverde et al. (2011), we adopted a conservative approach consisting of avoiding the overparameterization of models that could reduce their transferability to other spaces and increase omission error. Finally, a set of four climatic descriptors was used to fit SDMs, including the maximum temperature of the warmest quarter ('heat stress' - bio10), the minimum temperature of the coldest month ('cold stress' - bio6), the precipitation of the wettest quarter ('moisture stress' - bio16), and the precipitation of the driest quarter ('dry stress' - bio 17).

\section{Multivariate analysis}

We investigated climatic envelope divergence between conspecific lineages using multivariate analysis (Rivera et al. 2011). Such approaches depict the full variation of climatic variables and have none of the a priori assumptions inherent to modeling techniques (Legendre and Legendre 1998). For all species, we performed a principal component analysis followed by between-classes analysis (Dolédec and Chessel 1987) to compare climatic envelopes among lineages. Principal component analysis (PCA) is an ordination technique that maximizes the variance between individuals, whereas the between-classes analysis is a type of constrained PCA that maximizes both inter-individual and between-classes (here, the lineages) variance (Rossi and Blanchart 2005). We conducted multivariate analysis on 19 bioclimatic descriptors extracted from the Worldclim database for each occurrence. The climatic envelope associated to the invading population of $D$. valens (31 occurrences in China) was included in the multivariate analysis. We tested the significance of the between-classes structure using Monte Carlo permutation tests with 999 replications (Manly 2006). These multivariate analyses were computed using the ade4 package (Dray and Dufour 2007) in R ( R Development Core Team).

\section{Species distribution modeling}

We modeled the distributions of species and lineages using an approach based on the maximum entropy method (MaxEnt with default settings; Phillips et al. 2006) and a machine-learning approach based on the boosted regressions trees (BRT; Elith et al. 2008). These modeling techniques were selected because they are ranked among the bestperforming SDMs methods (Elith et al. 2006, Wisz et al. 2008). Both methods compare the climatic envelope experienced by a species with the climatic conditions found in locations where the species was undetected (i.e. pseudo-absences or background data). The positioning of background data is an important issue as it may significantly alter the predictions of models and must be set in accordance with the scale and the purpose of the study (VanDerWal et al. 2009, Anderson and Raza 2010). Since our study aims to assess invasion risk at the continent scale, we used wide background areas to enhance the transferability of models in other spaces (Elith et al. 2010). Both western part of North America and Central America were considered as background areas when modeling the distributions of $D$. brevicomis, D. pseudotsugae, D. ponderosae and the southern and western lineages of D. valens. The eastern part of North America was considered as a background area when modeling the distribution of the eastern lineage of $D$. valens. Finally, both North America and Central America were considered as background areas when modeling the distribution of $D$. rufipennis lineages. For MaxEnt, we randomly generated 10000 background points, excluding the sites where the species was detected (Phillips et al. 2006). For each BRT model, we generated a number of pseudo-absences similar to the number of occurrences used for model calibration in the same background areas, as previously described (Barbet-Massin et al. 2012).

For each lineage, we independently fitted 10 models using both algorithms (called lineage-based models), using 10 different training datasets constituted by random subsets of $80 \%$ of the relevant occurrences and pseudo-absences. The remaining $20 \%$ of data were used for model evaluation (see below). We performed ten replicates to reduce uncertainty of SDMs projections resulting from the random partitioning of occurrences into calibration and evaluation datasets (Phillips et al. 2006). Subsequently, we pooled all occurrences from conspecific lineages to calibrate classical species models ('species-based models'). Similarly, each algorithm was run 10 times, using the same ratio of training/ evaluation data. In each case, we constructed an additional prediction map by calculating the mean climatic suitability index displayed by the 10 models, which corresponded to the same species lineage. All climatic suitability maps were converted into binary maps of presence/absence on the basis of a single threshold. We used the lowest presence threshold (LPT; Pearson et al. 2007), a particular case of the minimum required sensitivity method (Pearson et al. 2004), that is well-adapted for SDMs designed to assess the risk of biological invasion for which omission errors have to be avoided (Freeman and Moisen 2008, Webber et al. 2011). A pixel was considered as climatically suitable for one lineage if more than $50 \%$ of the lineage-based models predicted this pixel as suitable (i.e. at least six out of 10 models). Finally, for 
each species, an aggregated binary prediction was obtained by assigning a presence to each pixel that was predicted as climatically suitable for at least one lineage.

The predictive performance of the models was evaluated using the remaining $20 \%$ of available occurrences and pseudo-absences/background points. We calculated the area under the receiver-operator curve (AUC), which is a widely used threshold-independent evaluation measure (Fielding and Bell 1997). Since the use of AUC in species distribution modeling is debated (Lobo et al. 2010, Jiménez-Valverde 2012), we additionally calculated the continuous Boyce index, which is a reliable presence-only evaluation measure that is relatively insensitive to species prevalence (Hirzel et al. 2006). We computed multivariate environmental similarity surface (MESS) maps that describe the similarity in climatic space between the projected and the fitted areas (Elith et al. 2011). Models and computations were performed using the 'dismo' (Hijmans et al. 2013) and 'gbm' (Ridgeway and Ridgeway 2004) packages in R.

\section{Niche similarity and equivalency tests}

In addition to multivariate analysis, we quantified the degree of niche similarity between conspecific lineages by implementing the niche comparison framework developed by Broennimann et al. (2012). We applied a smoother kernel to the densities of species occurrences in bioclimatic raster maps and subsequently calculated the metrics of niche overlap and tested niche conservatism hypotheses. We calculated Schoener's D index to measure the overlap of the SDMs projections, which varies from 0 for non-overlapping model predictions to 1 for complete overlap (Schoener 1968). Niche equivalency and similarity hypotheses were then tested using the algorithm MaxEnt.

The equivalency test aims to investigate whether the niches occupied by two lineages are equivalent. In this randomization test, we pooled and randomly split lineages occurrences in two datasets (maintaining the number of occurrences as in the original datasets) and measured niche overlap D value with these datasets (this procedure was repeated 100 times). The observed $\mathrm{D}$ value was then compared against the distribution of the 100 simulated $\mathrm{D}$ values. If the observed $\mathrm{D}$ value fell outside the distribution of the simulated $\mathrm{D}$ values, niche equivalency hypothesis was rejected (Broennimann et al. 2012). The niche similarity test investigates whether the niches occupied by two lineages are more similar than expected by chance. For this randomization test, the observed density of occurrences relative to one lineage was shifted within the geographic range available for this lineage. Then, we calculated the overlap $\mathrm{D}$ value between this simulated niche and the niche occupied by the other lineage (this procedure was repeated 100 times). If the observed $\mathrm{D}$ value is greater than $95 \%$ of the simulated $\mathrm{D}$ values, niches of lineages are considered as more similar than expected by chance (Broennimann et al. 2012). In these tests, we did not use the previously described background areas to generate pseudo-absences because investigating niche divergence among taxonomic entities require avoiding as much as possible sampling absences in a region where the taxa are not present because of dispersal limitations or biogeographic events rather than for climatic unsuitability (Barve et al. 2011, Broennimann et al. 2012). In previous lineage-based SDMs, we mainly aimed to highlight the relative contributions of conspecific lineages in the potential distribution of pests and thus generated pseudo-absences in regions occupied by other conspecific lineages when modeling the distribution of a lineage. Here, selecting the background regions previously used in lineage-based models could lead to an artefactual inflation of niche divergence signal. For these analyses, we generated pseudo-absences in smallest background areas considering potential geographic barriers and past biogeographic events (Supplementary material Appendix 2).

\section{Results}

\section{Realized niches differ among conspecific lineages}

Graphical displays of PCAs (correlation circles and score plots) and the percentages of total inertia explained by the factorial axes are given in Fig. 1, 2 and Supplementary material Appendix 2, Fig. A3a-c. According to the Monte Carlo permutation tests, there was a significant difference between conspecific lineages $(\mathrm{p}<0.001)$. The PCAs discriminated lineages of $D$. valens, $D$. pseudotsugae, $D$. rufipennis according to temperature-related variables such as minimum temperatures (bio6, bio11) and temperature seasonality (bio2, bio3, bio4, see Fig. 1, and Supplementary material Appendix 2, Fig. A3a, b). The envelope of the invading populations of $D$. valens in China was closer to the envelopes of the northeastern and western lineages of $D$. valens than that of the southern lineage (Fig. 1). Between-class PCA applied to $D$. brevicomis dataset was significant and revealed that the mean temperatures of the wettest and the driest quarters (bio8, bio9), the precipitation of the wettest and the warmest quarters (bio16, bio18) and the precipitation of the coldest quarter (bio19) contributed to segregate the lineages. The mean temperature of the wettest and driest quarters (bio8, bio9), the annual temperature range (bio7) and the precipitation of the coldest quarter (bio19) separated conspecific lineages of D. ponderosae.

The formal tests of niche equivalency indicated significant realized niche differences among conspecific lineages in all Dendroctonus species (Supplementary material Appendix 2, Fig. A4). Interestingly, albeit different, the realized niches of lineages were estimated to be more similar than expected by chance in all species (niche similarity tests, Supplementary material Appendix 2, Fig. A4).

\section{Potential geographical distributions}

All models yielded an AUC above 0.68. Most of models displayed a continuous Boyce index greater than 0 , indicating that these models better predict the presences of the evaluation dataset than a random model (Supplementary material Appendix 2, Table A5). Only several BRT models calibrated for $D$. pseudotsugae barragani displayed a Boyce index less than 0 , warranting caution when interpreting these models. This probably resulted from the limited number of occurrences available for this subspecies. The ten SDMs replicates 

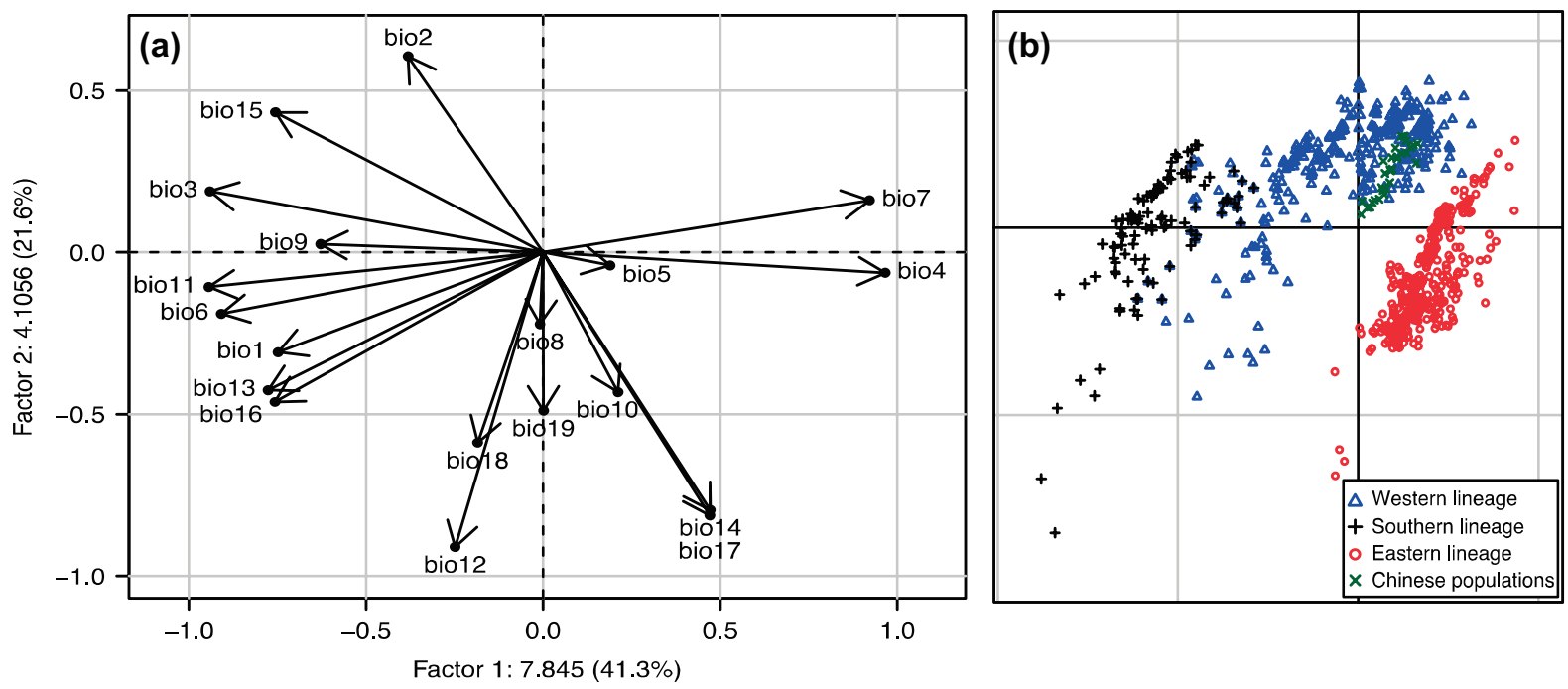

Figure 1. Principal components analysis of climatic data extracted from Dendroctonus valens occurrences from the Worldclim database (Hijmans et al. 2005; see Table 2 for symbol meanings). Circles of correlation (a) and factorial scores of records (b) are represented. Red circles, blue triangles and black crosses represent individuals assigned to the eastern, western and southern lineages, respectively. Green crosses represent invading populations.

displayed similar but non-equivalent binary predictions (Supplementary material Appendix 2, Fig. A6 and A7), highlighting the need to account for uncertainty associated with occurrence partitioning when transforming climatic suitability maps into binary presence/absence maps. Most of the projected area displayed positive MESS values, indicating a low level of climatic dissimilarity between the training climatic space and the projected area in Europe. Both modeling approaches showed similar trends and congruent projections (Fig. 4 and Supplementary material Appendix 2, Fig. A6 and A7) except for the subspecies D. p. barragani (Supplementary material Appendix 2, Fig. A6c and A7c).

Similar areas were predicted to be climatically suitable in Europe for $D$. ponderosae, D. valens, $D$. pseudotsugae and $D$. brevicomis (Fig. 3, 4, and Supplementary material Appendix 2, Fig. A6 and A7). As expected, the distributions of suitable climatic conditions for $D$. rufipennis were predicted in colder areas of Eurasia at northern latitudes and in mountainous ranges (Fig. 3, and Supplementary material Appendix 2, Fig. $\mathrm{A} 6 \mathrm{c}$ and $\mathrm{A} 7 \mathrm{c})$. Model predictions indicated that conspecific lineages differed in the potential area that was predicted to be climatically suitable in Europe for all species (Fig. 3, 4, and Supplementary material Appendix 2, Fig. A3, A4 and A5). In some cases, differences among lineages were very slight (e.g. D. brevicomis). Dendroctonus valens and D. pseudotsugae showed the lowest level of overlap of predicted climatic suitability among conspecific lineages (Fig. 3 and 4). The entire invaded range of $D$. valens was not predicted as climatically suitable for the three lineages (Fig. 4). Most of the invaded range of D. valens $(100 \%$ and $93.5 \%$ of the occurrences in China for MaxEnt and BRT models, respectively) was predicted to be climatically suitable by the models,
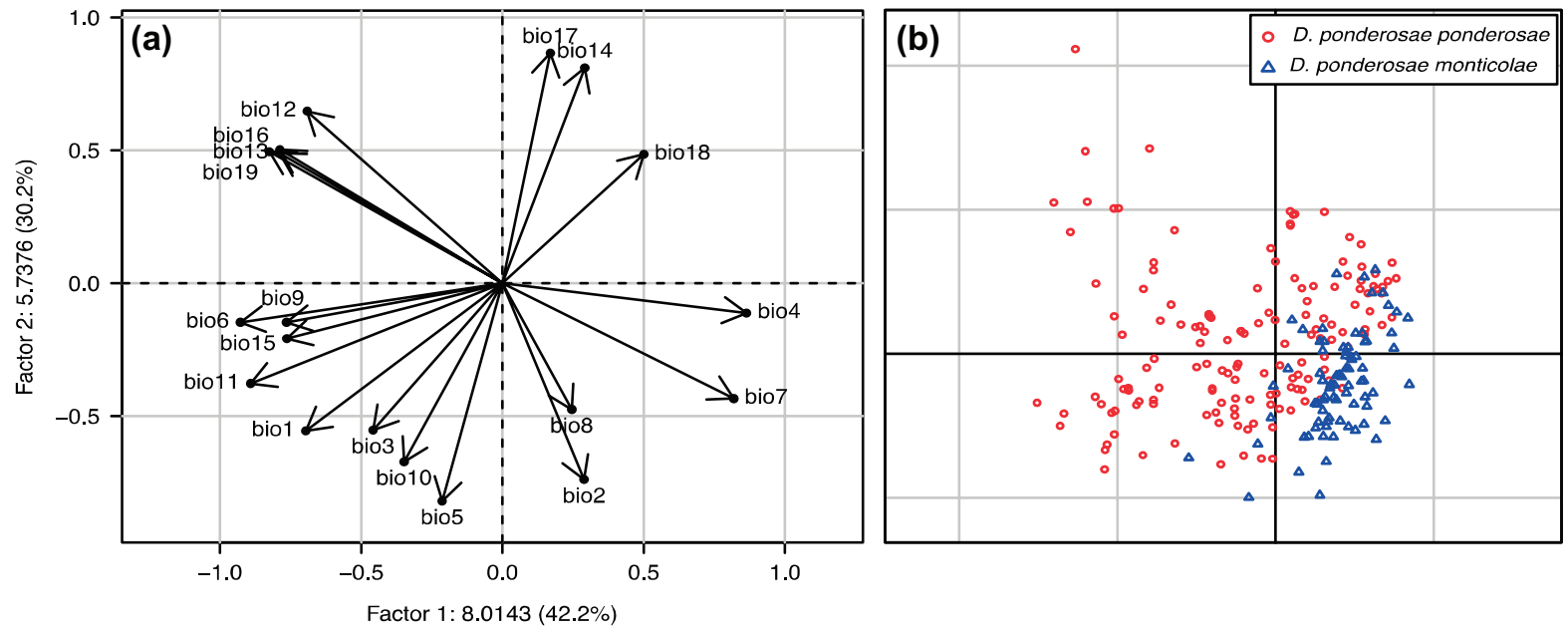

Figure 2. Principal components analysis of climatic data extracted from Dendroctonus ponderosae occurrences from the Worldclim database (Hijmans et al. 2005; see Table 2 for symbol meanings). Circles of correlation (a) and factorial scores of records (b) are represented. Red circles and blue triangles represent individuals assigned to the lineages ponderosae and monticolae, respectively. 
(a) Species

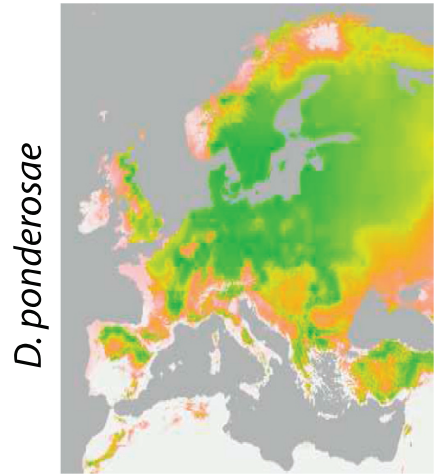

(d) Species

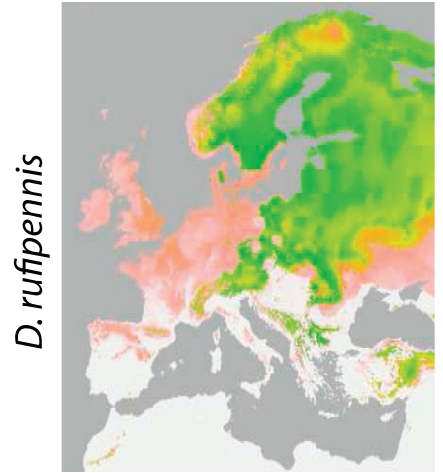

(g) Species

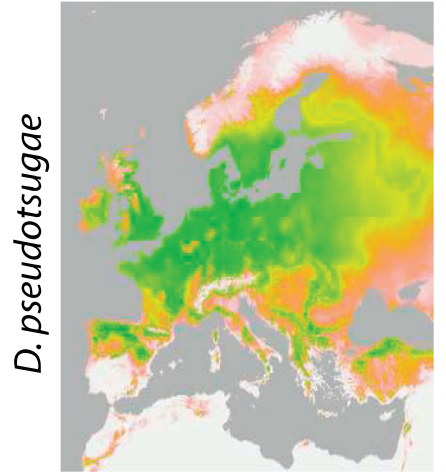

(j) Species

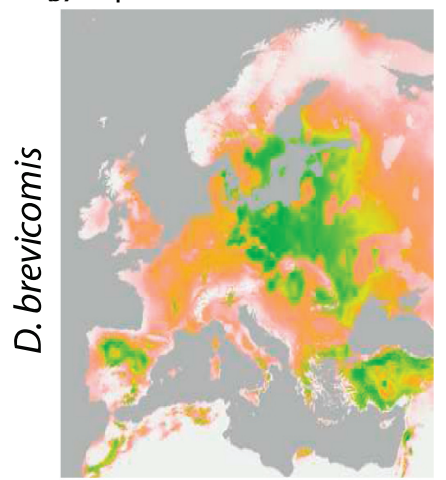

(b) ponderosae lineage

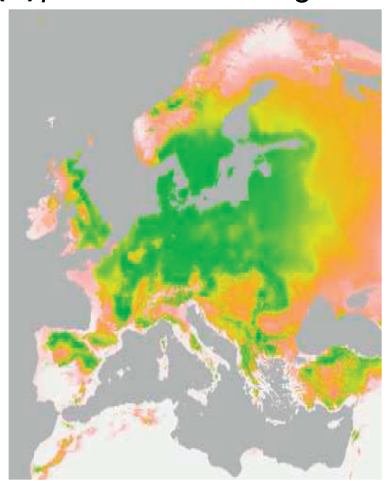

(e) P. glauca lineage

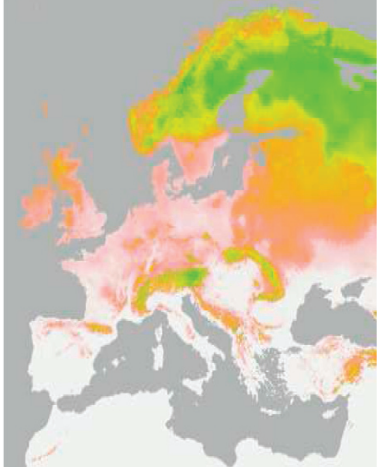

(h) D. p. pseudotsugae

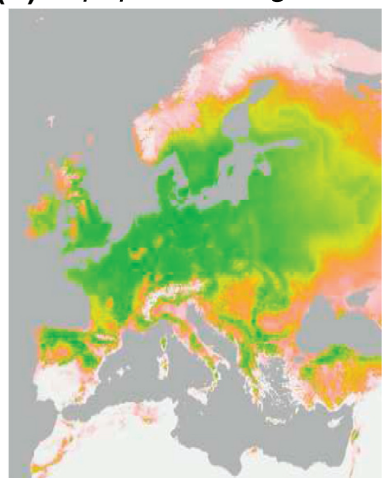

(k) P. p. scopulorum lineage (I) P. p. ponderosae lineage

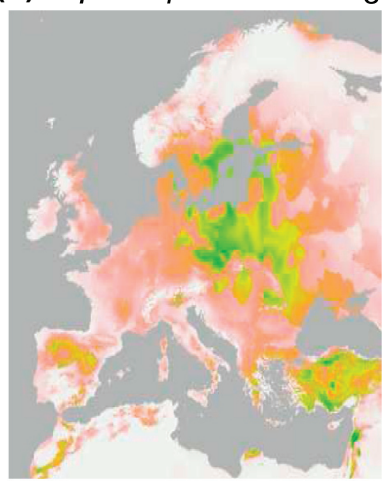

(c) monticolae lineage

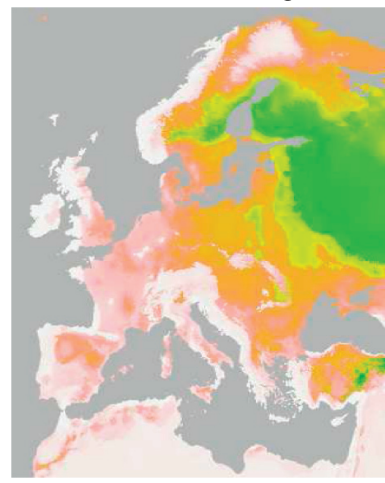

(f) $P$. engelmannii lineage

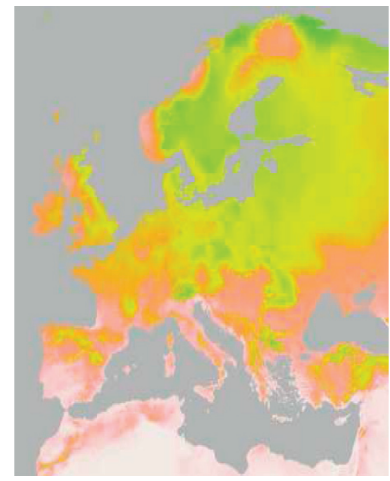

(i) D. p. barragani
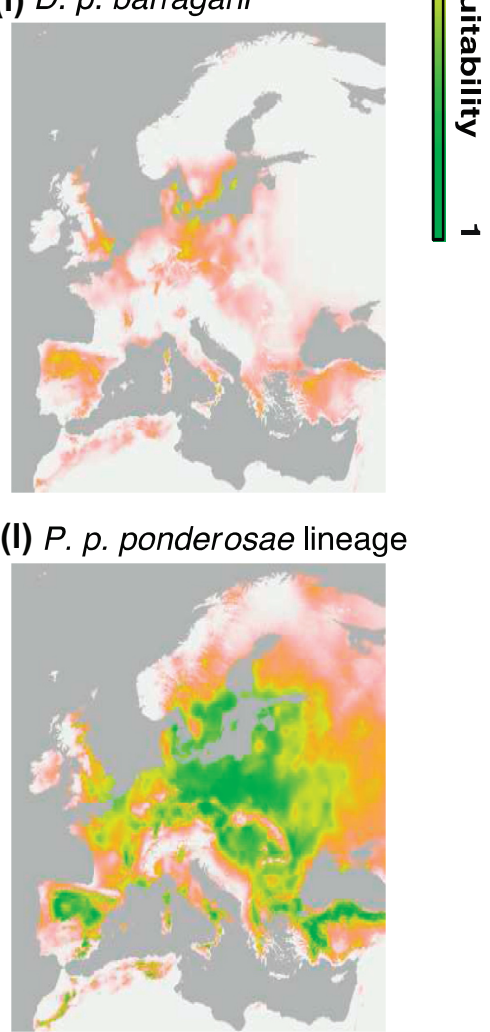

Figure 3. Potential distribution of four Dendroctonus species (D. brevicomis, D. pseudotsugae, D. rufipennis, D. ponderosae) in Europe predicted by MaxEnt models. For each lineage, we calibrated 10 models. Map projections display the arithmetic mean of climatic suitability values predicted by the 10 replicates. 
(a) Species
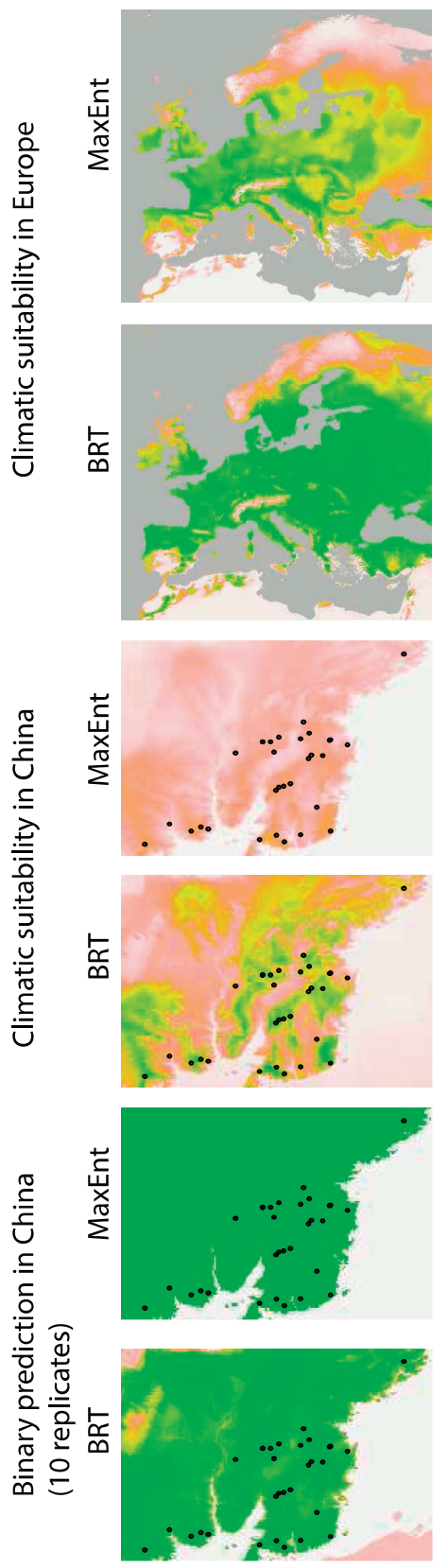

(b) Eastern lineage
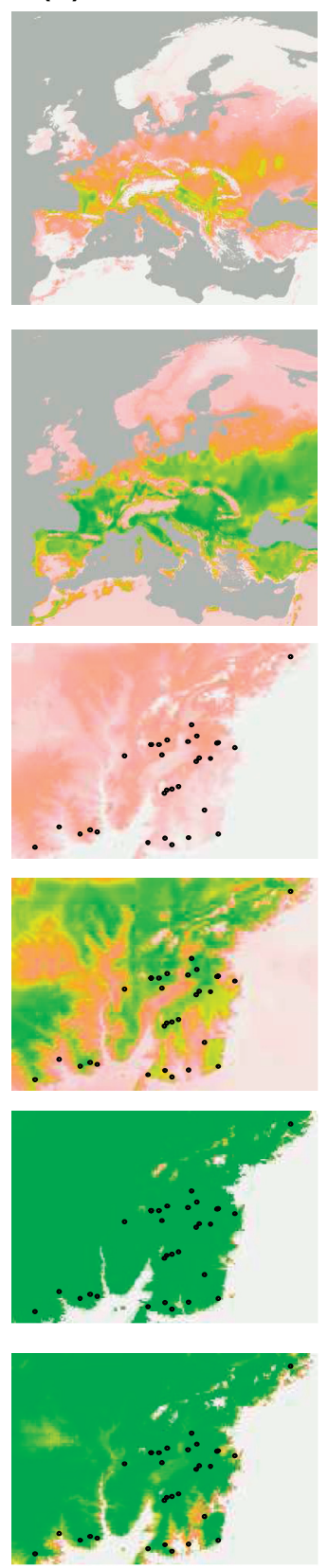

(c) Western lineage
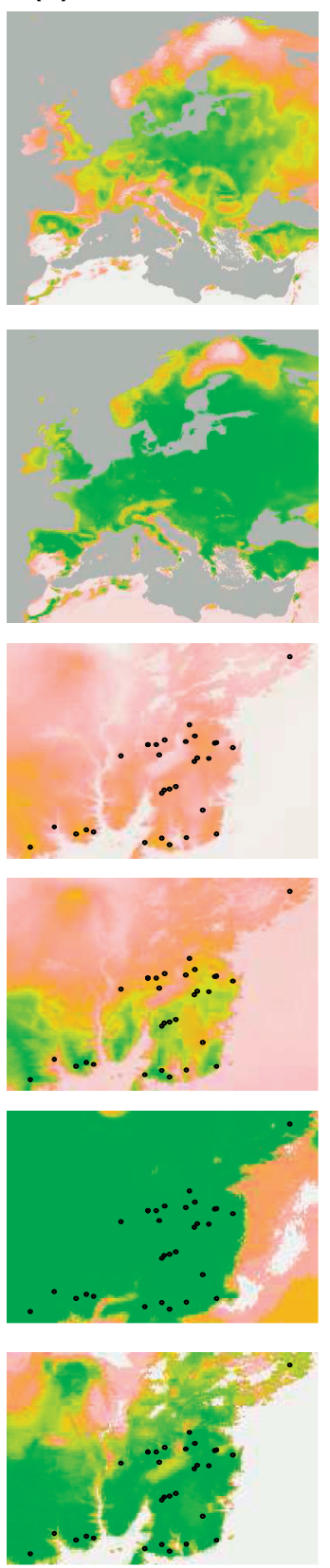

(d) Southern lineage
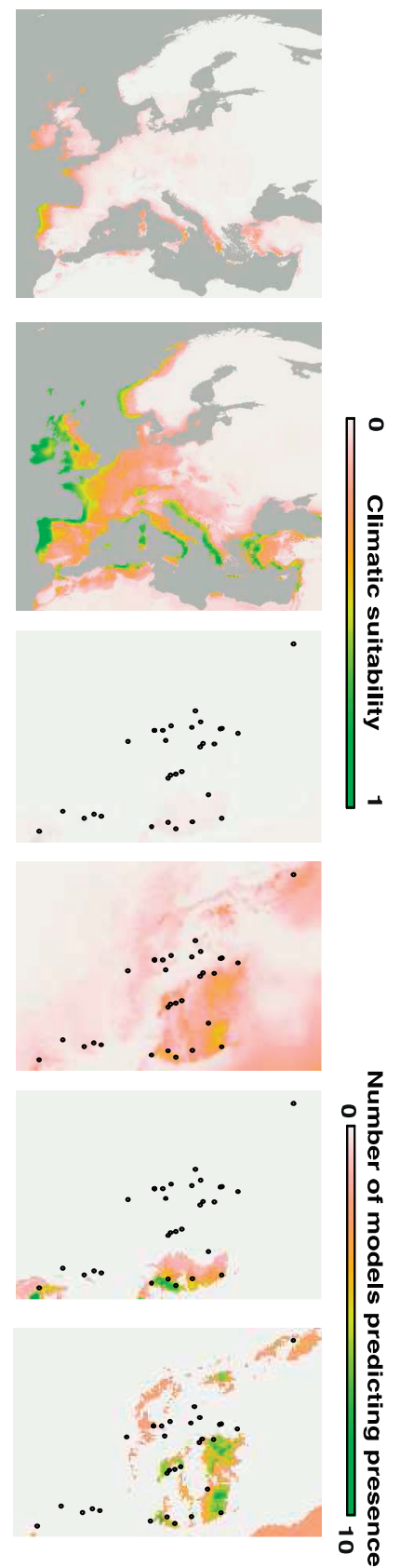

Figure 4. Potential distribution of Dendroctonus valens in Europe and in China predicted by the MaxEnt and BRT models. For each lineage, we calibrated 10 models with both algorithms. Binary maps of presence/absence were constructed using the lowest presence threshold (Pearson et al. 2007). The first four rows show map projections displaying the arithmetic mean of climatic suitability values predicted by the 10 replicates. The last two rows show maps indicating the number of models predicting a presence when implementing the threshold. Black dots represent occurrences in the invaded range.

corresponding to the eastern and western lineages (Fig. 4). On the contrary, most of the invaded range was predicted to be climatically unsuitable for the southern lineage (Fig. 4).

The distributions of suitable climate predicted by speciesbased models and aggregated binary projections did not perfectly overlap (Fig. 5, Table 3 and Supplementary material Appendix 2, Fig. A8). Differences varied in both magnitude (number of pixels that change status when comparing classical species-based predictions and aggregated binary projections) and direction (the number of pixels with predicted presences in aggregated binary projections may be higher or lower than in classical species-based predictions), according to the species and the SDM approach (Table 3). Mismatches usually concerned a small percentage of the total area that was predicted as climatically suitable (Table 3 ). For example, for $D$. pseudotsugae, differences between aggregated binary projections and species-based models predictions did not exceed $16 \%$ of the geographic extent that was considered suitable by one approach (Table 3, and Supplementary material Appendix 2, Fig. A8). However, in a few cases, aggregated 

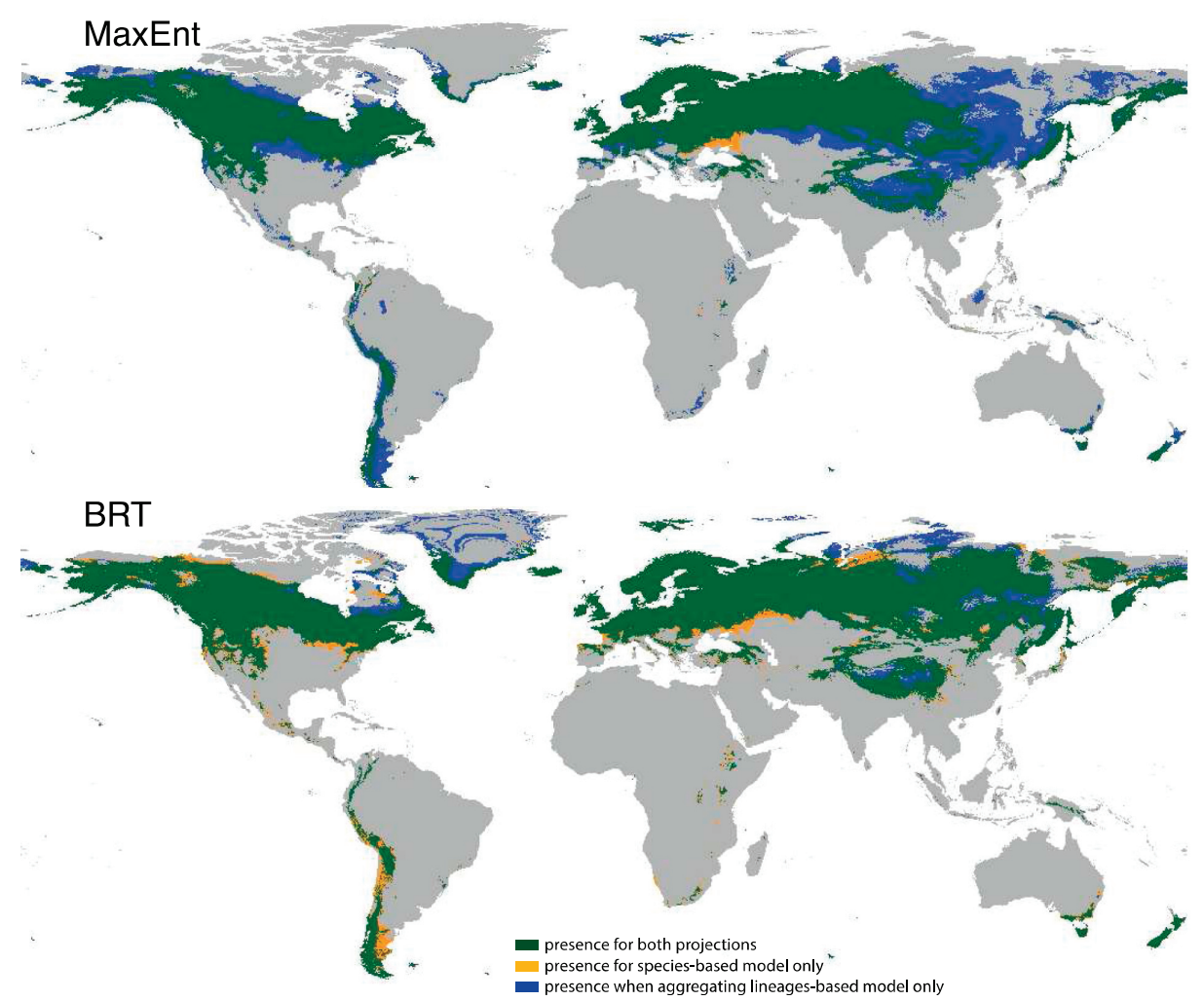

Figure 5. Maps showing the change in worldwide suitable climatic conditions when aggregating the binary predictions of lineage-based models of Dendroctonus rufipennis. These predictions were compared with the classical species-based models. These projections were obtained by assigning a presence to each pixel that was predicted as being climatically suitable for at least one lineage. A pixel was considered as climatically suitable for one lineage if more than $50 \%$ of the lineage-based models (i.e. at least six out of 10 models) predicted this pixel as suitable when implementing the lowest presence threshold (Pearson et al. 2007).

binary models and species-based models showed differences in prediction up to $44 \%$ of the geographic extent that was considered suitable by one model (e.g. D. rufipennis; Table 3, Fig. 5).

\section{Discussion}

\section{Realized niche of conspecific lineages: similar but not equivalent}

This study shows that the realized niches of conspecific lineages of all Dendroctonus species were more similar than expected by chance, without thereby being equivalent. Similarity means that species include lineages sharing similar realized niches at continent-scale (Warren et al. 2008, 2014). On the opposite, the absence of equivalency implies that although close, the realized niches are not identical and that lineages display significant differences with respect to the bioclimatic variables involved in species distribution modeling.

The phylogeographic structure of Dendroctonus species has been probably shaped by glaciations that fragmented their host-plant ranges and reduced gene flow between populations from different glacial refugia (Maroja et al. 2007). During their full-glacial isolation in refugia and subsequent

Table 3. Percentage of change (number of pixels) in worldwide suitable climatic conditions when aggregating binary predictions of lineagebased models. These predictions were compared with the classical species-based models. These projections were obtained by assigning a presence to each pixel that was predicted as climatically suitable for at least one lineage. A pixel was considered as climatically suitable for one lineage if more than $50 \%$ of the IS-models (i.e. at least six out 10 models) predicted this pixel as suitable when implementing the lowest presence threshold (Pearson et al. 2007).

\begin{tabular}{lcccc}
\hline & \multicolumn{3}{c}{ Modeling approach } \\
\cline { 2 - 5 } Species & \multicolumn{2}{c}{ MaxEnt } & & BRT \\
\cline { 2 - 5 } & \% pixels gained & \% pixels lost & & \% pixels gained \\
\hline Dendroctonus brevicomis & 16.96 & 12.205 & 13.289 & \% pixels lost \\
Dendroctonus ponderosae & 4.526 & 23.233 & 3.963 & 15.687 \\
Dendrocotnus rufipennis & 44.12 & 1.313 & 11.932 & 27.863 \\
Dendroctonus pseudotsugae & 6.818 & 1.225 & 5.727 & 7.246 \\
Dendroctonus valens & 24.373 & 9.49 & 18.375 & 2.526 \\
\hline
\end{tabular}


post-glacial recolonization, phylogeographic lineages have mostly conserved the climatic tolerances of their ancestors. Nowadays, lineages occur in geographical areas differing with regards to bioclimatic descriptors leading to significant departure from niche equivalency sensu Broennimann et al. (2012). The observed differences in the realized climatic niches do not necessarily mean that the fundamental niches have diverged (Araújo and Peterson 2012). Various factors such as biotic interactions and spatial constraints, affect the occupancy of the fundamental niche that may lead to dissimilarities in realized niche. Biotic factors include interspecific relationships with host trees, competitors, parasitoids or fungal symbionts that are obligate for numerous bark beetles (Six 2012). Some recent results on vertebrates indicate that the thermal component of the fundamental niche is more conserved than usually deduced from SDMs (Araújo et al. 2013). If this is also true for bark beetles, it would imply that the observed differences of realized niches mostly convey patterns of niche occupation.

If niche differences correspond to discrepancies in fundamental niche between conspecific lineages, physiological adaptations to local conditions could be expected and this would be meaningful in terms of invasion risk. Since the intraspecific genetic structure is usually inferred from the use of neutral molecular markers, it is not directly informative concerning effective physiological adaptations to environment. There is increasing evidence that recently evolved populations within widespread species, including those from Dendroctonus and Pinus, show significant geneticbased adaptations to local conditions (Rehfeldt et al. 1999, Savolainen et al. 2007, Rey et al. 2012, Bentz et al. 2014, Janes et al. 2014). However, the potential contributions of these adaptations to invasion success remain to be explored using physiological and genomic approaches (Fitzpatrick and Keller 2014, Janes et al. 2014). Finally, because the invasiveness of phytophagous insects in one area results from numerous interdependent factors, e.g. life-history traits, propagule pressure and host specificity (Leung et al. 2012, Bacon et al. 2014), additional data concerning the ecological and biological specificities of lineages should also be integrated into invasion risk assessments.

\section{Dendroctonus species as potential invasive organisms: the threat is real}

Dendroctonus species require particular attention from biosecurity agencies, since they are highly damaging pests responsible for huge economic losses in their native and invaded ranges (Yan et al. 2005). To our knowledge, this study is the first to predict the potential distribution in Europe of harmful Dendroctonus using SDMs. Our predictions strongly suggest that most of Europe offers climatic conditions suitable for the Dendroctonus species considered in this study. In addition, the large diversity of conifers occurring in Europe increases the probability that some Dendroctonus species may become invasive. However, climatic tolerances are not the only factors determining the invasive potential of these bark beetles. Most species also depend upon obligate fungal symbionts whose climatic tolerances might also influence their distributions (Addison et al. 2013). Propagule pres- sure is another factor that determines the invasive potential of insects (Lockwood et al. 2005, Bacon et al. 2014). This is certainly true for some Dendroctonus (e.g. D. ponderosae) that mass-attack trees. The success of such species highly depends on the number of introduced propagules. However, propagule pressure required to invade a new region likely differ among species (e.g. D. valens, the only North American Dendroctonus that invaded a new area, is a solitary attacker that does not mass-attack trees).

Our results indicate that the threat is real when we consider the potential invasiveness of Dendroctonus species. The species-based bioclimatic models fitted to $D$. valens dataset accurately predicted the invaded range thus suggesting that the climatic niche of this species has been conserved during its invasion of China. This highlights the reliability of our projections to predict the invaded range by this species. Moreover, these results are in accordance with the general expectation of niche conservatism during invasions (Peterson 2011, Petitpierre et al. 2012, Strubbe et al. 2013).

\section{Integrating intraspecific genetic structure in species distribution modeling}

Our results showed that integrating phylogeographical information into SDMs potentially alters the classical species-based invasion risk assessment. We observed that binary predictions constructed by aggregating the lineagebased model predictions could differ from binary speciesbased predictions. The directions and the magnitude of these changes appeared to be dependent both on the species and the modeling approaches. Similar trends have been observed when integrating the phylogeographic structure of species into SDMs to design conservation plans (Pearman et al. 2010, D'Amen et al. 2013). These surveys suggested that species-based models tend to smooth out the climatic response curves specific to the different lineages. Although differences between predictions were relatively slight in most cases, such features could have practical importance for plant biosecurity agencies when designing costly quarantine measures and prevention plans against invasive species.

Here we report that several species show strong intraspecific divergence in the climatic envelope. Indeed, latitudinally-separated lineages (e.g. D. valens, D. pseudotsugae, $D$. rufipennis) occurred in areas that strongly differed in winter temperatures and seasonal structure of climate, e.g. the mean temperature of the coldest month experienced by $D$. pseudotsugae ranged from 5.9 to $-4.9^{\circ} \mathrm{C}$ in Mexico and from 5.5 to $-18.8^{\circ} \mathrm{C}$ in northwestern America. Consequently, SDMs predicted different geographic areas across Europe as being climatically suitable for lineages. This illustrates how lineage-based SDMs could highlight the different contributions of lineages in the predicted potential distribution of species. We recognize that these observations do not indicate that lineages display different potential distributions since SDMs do not depict the fundamental niches of species. However, it warrants investigating the climatic preferences and potential adaptations of phylogeographic lineages to environment in order to improve the PRAs' reliability. 


\section{Towards improved PRA?}

Recent studies highlighted the poor performance of lineagebased modeling approaches in describing an invasion process (e.g. the inability of lineage-based SDMs to predict the entire invaded range of a species; Thompson et al. 2011, Schulte et al. 2012, Beaumont et al. 2014). Interestingly, the relevance of such tools is still debated and requires validation through analyses of past or ongoing invasions. Since the intraspecific identity of $D$. valens populations that have invaded China has been elucidated (Cognato et al. 2005, Cai et al. 2008), this species provided the opportunity to test the lineage-based approach using a successful invasion. Genetic analyses suggested western America as the most likely origin of the invading population (Cai et al. 2008) and our SDM analyses came to a similar conclusion. We observed, indeed, a high climatic similarity between the areas occupied by $D$. valens in western America and China suggesting that lineages' preadaptations to climate might have played a crucial role during this invasion. There is increasing evidence that preadaptations to environment increase the probability of initial establishment of introduced populations in a new region (Duncan et al. 2001, Lachmuth et al. 2010, Rey et al. 2012). Since invasion of $D$. valens is relatively recent, it is difficult to determine whether spread of the invasive lineage would be prevented or at least slowed in regions predicted as more climatically suitable for the other lineages by our SDMs. A close monitoring of the spread of $D$. valens in China would be of help to clarify this question.

Pest risk analysis would benefit from improved SDM projections based on the aggregated predictions obtained for each lineage. Another idea would be to dedicate more resources to inspect goods originating from regions associated to lineages showing higher risk. This invasion management option might reduce the number of new invaders since there is increasing evidence that intraspecific units may display preadaptations to different climatic conditions and thus contrasted risk of establishment in new geographic regions especially when populations densities are low as it is usually the case during the first phases of invasions (Rey et al. 2012). However, the success of this management option is uncertain since pests might be transported from one region to another within a country (in reason for intranational exchange) before being introduced into other countries. Finally, molecular tools allowing rapid and precise identification of intercepted organisms are increasingly available to plant biosecurity agencies (e.g. DNA barcoding; Armstrong and Ball 2005, Coeur d'acier et al. 2014). These tools allow the identification of the organisms and the identification of the lineage they belong to. If lineages differ in the risk they are associated to, then the design of management plans could be adapted to the organism soon after interception. If intraspecific climatic niche divergence is undoubtedly demonstrated, we suggest that quarantine status or management plans might differ among conspecific lineages. For these reasons, lineage-based approaches should be considered whenever possible i.e. when consistent phylogeographic analyses are available together with a sufficient amount of occurrence data enabling SDM analysis.
Acknowledgements - The work was supported by a grant from the Inst. National de la Recherche Agronomique through the research program SMaCH (Sustainable Management of Crop Health). We are indebted to the editor and Andrea Sanchez Meseguer for their insightful comments and suggestions.

\section{References}

Addison, A. et al. 2013. The role of temperature variability in stabilizing the mountain pine beetle-fungus mutualism. - J. Theor. Biol. 335: 40-50.

Anderson, R. P. and Raza, A. 2010. The effect of the extent of the study region on GIS models of species geographic distributions and estimates of niche evolution: preliminary tests with montane rodents (genus Nephelomys) in Venezuela. - J. Biogeogr. 37: 1378-1393.

Anducho-reyes, M. et al. 2008. Phylogeography of the bark beetle Dendroctonus mexicanus Hopkins (Coleoptera: Curculionidae: Scolytinae). - Mol. Phylogenet. Evol. 49: 930-940.

Araújo, M. B. and Peterson, A. T. 2012. Uses and misuses of bioclimatic envelope modeling. - Ecology 93: 1527-1539.

Araújo, M. B. et al. 2013. Heat freezes niche evolution. - Ecol. Lett. 16: 1206-1219.

Armstrong, K. and Ball, S. 2005. DNA barcodes for biosecurity: invasive species identification. - Phil. Trans. R. Soc. B 360: 1813-1823.

Avise, J. C. et al. 1987. Intraspecific phylogeography: the mitochondrial DNA bridge between population genetics and systematics. - Annu. Rev. Ecol. Syst. 18: 489-522.

Bacon, S. J. et al. 2014. Quarantine arthropod invasions in Europe: the role of climate, hosts and propagule pressure. - Divers. Distrib. 20: 84-94.

Barbet-Massin, M. et al. 2012. Selecting pseudo-absences for species distribution models: how, where and how many? - Methods Ecol. Evol. 3: 327-338.

Barve, N. et al. 2011. The crucial role of the accessible area in ecological niche modeling and species distribution modeling. - Ecol. Model. 222: 1810-1819.

Beaumont, L. J. et al. 2014. How can knowledge of the climate niche inform the weed risk assessment process? A case study of Chrysanthemoides monilifera in Australia. - Divers. Distrib. 20: 613-625.

Benito Garzón, M. et al. 2011. Intra-specific variability and plasticity influence potential tree species distributions under climate change. - Global Ecol. Biogeogr. 20: 766-778.

Bentz, B. et al. 2014. Mountain pine beetle voltinism and life history characteristics across latitudinal and elevational gradients in the western United States. - For. Sci. 60: 434-449.

Bracewell, R. R. et al. 2011. Cryptic postzygotic isolation in an eruptive species of bark beetle (Dendroctonus ponderosae). - Evolution 65: 961-975.

Broennimann, O. et al. 2007. Evidence of climatic niche shift during biological invasion. - Ecol. Lett. 10: 701-709.

Broennimann, O. et al. 2012. Measuring ecological niche overlap from occurrence and spatial environmental data. - Global Ecol. Biogeogr. 21: 481-497.

Cai, Y.-W. et al. 2008. Genetic diversity and biogeography of red turpentine beetle Dendroctonus valens in its native and invasive regions. - Insect Sci. 15: 291-301.

Coeur d'acier, A. et al. 2014. DNA barcoding and the associated PhylAphidB@se website for the identification of European aphids (Insecta: Hemiptera: Aphididae). - PLoS One 9: e97620.

Cognato, A. I. et al. 2005. Genetic variation and origin of red turpentine beetle (Dendroctonus valens LeConte) introduced to the People's Republic of China. - Agric. For. Entomol. 7: 87-94. 
Cullingham, C. I. et al. 2011. Mountain pine beetle host-range expansion threatens the boreal forest. - Mol. Ecol. 20: 2157-2171.

Cullingham, C. I. et al. 2012. Phylogeographic insights into an irruptive pest outbreak. - Ecol. Evol. 2: 908-919.

D'Amen, M. et al. 2013. Conservation of phylogeographic lineages under climate change. - Global Ecol. Biogeogr. 22: 93-104.

Devorshak, C. 2012. Plant pest risk analysis: concepts and applications. - Cabi.

Dolédec, S. and Chessel, D. 1987. Rythmes saisonniers et composantes stationnelles en milieu aquatique. I: description d'un plan d'observation complet par projection de variables. - Acta Oecol. 8: 403-426.

Dormann, C. F. et al. 2013. Collinearity: a review of methods to deal with it and a simulation study evaluating their performance. - Ecography 36: 27-46.

Dray, S. and Dufour, A.-B. 2007. The ade4 package: implementing the duality diagram for ecologists. - J. Stat. Softw. 22: 1-20.

Duncan, R. P. et al. 2001. High predictability in introduction outcomes and the geographical range size of introduced Australian birds: a role for climate. - J. Anim. Ecol. 70: 621-632.

Elith, J. and Leathwick, J. R. 2009. Species distribution models: ecological explanation and prediction across space and time. - Annu. Rev. Ecol. Evol. Syst. 40: 677-697.

Elith, J. et al. 2006. Novel methods improve prediction of species' distributions from occurrence data. - Ecography 29: 129-151.

Elith, J. et al. 2008. A working guide to boosted regression trees. - J. Anim. Ecol. 77: 802-813.

Elith, J. et al. 2010. The art of modelling range-shifting species. - Methods Ecol. Evol. 1: 330-342.

Elith, J. et al. 2011. A statistical explanation of MaxEnt for ecologists. - Divers. Distrib. 17: 43-57.

Fielding, A. H. and Bell, J. F. 1997. A review of methods for the assessment of prediction errors in conservation presence/ absence models. - Environ. Conserv. 24: 38-49.

Finnoff, D. et al. 2007. Take a risk: preferring prevention over control of biological invaders. - Ecol. Econ. 62: 216-222.

Fitzpatrick, M. C. and Keller, S. R. 2014. Ecological genomics meets community-level modelling of biodiversity: mapping the genomic landscape of current and future environmental adaptation. - Ecol. Lett. doi: 10.1111/ele. 12376

Freeman, E. A. and Moisen, G. G. 2008. A comparison of the performance of threshold criteria for binary classification in terms of predicted prevalence and kappa. - Ecol. Model. 217: $48-58$.

Godefroid, M. et al. 2015. Assessing the risk of invasion by Tephritid fruit flies: intraspecific divergence matters. - PLos One 10: e0135209.

Grout, T. G. and Stoltz, K. C. 2007. Developmental rates at constant temperatures of three economically important Ceratitis spp. (Diptera: Tephritidae) from southern Africa. - Environ. Entomol. 36: 1310-1317.

Guisan, A. et al. 2014. Unifying niche shift studies: insights from biological invasions. - Trends Ecol. Evol. 29: 260-269.

Hewitt, G. M. 1996. Some genetic consequences of ice ages, and their role in divergence and speciation. - Biol. J. Linn. Soc. 58: 247-276.

Hijmans, R. J. et al. 2005. Very high resolution interpolated climate surfaces for global land areas. - Int. J. Climatol. 25: 1965-1978.

Hijmans, R. J. et al. 2013. dismo. Species distribution modeling. - R package ver. 0.9-3.

Hill, M. P. et al. 2013. A predicted niche shift corresponds with increased thermal resistance in an invasive mite, Halotydeus destructor. - Global Ecol. Biogeogr. 22: 942-951.

Hirzel, A. H. et al. 2006. Evaluating the ability of habitat suitability models to predict species presences. - Ecol. Model. 199: 142-152.
Hopkins, A. D. 1909. Contributions toward a monograph of the Scolytid beetles. The genus Dendroctonus. - US Government Printing Office, US Bureau of Entomology Technical Series Washington, no. 17, part 1: 1-164.

Hutchinson, G. E. 1957. Concluding remarks. - Cold Spring Harbor Symp. Quant. Biol. 22: 415-427.

Janes, J. K. et al. 2014. How the mountain pine beetle (Dendroctonus ponderosae) breached the Canadian Rocky Mountains. - Mol. Biol. Evol. 31: 1803-1815.

Jiménez-Valverde, A. 2012. Insights into the area under the receiver operating characteristic curve (AUC) as a discrimination measure in species distribution modelling. - Global Ecol. Biogeogr. 21: 498-507.

Jiménez-Valverde, A. et al. 2011. Use of niche models in invasive species risk assessments. - Biol. Invasions 13: 2785-2797.

Kelley, S. T. et al. 1999. Strong differentiation in mitochondrial DNA of Dendroctonus brevicomis (Coleoptera: Scolytidae) on different subspecies of ponderosa pine. - Ann. Entomol. Soc. Am. 92: 193-197.

Kozak, K. H. and Wiens, J. 2006. Does niche conservatism promote speciation? A case study in North American salamanders. - Evolution 60: 2604-2621.

Lachmuth, S. et al. 2010. The making of a rapid plant invader: genetic diversity and differentiation in the native and invaded range of Senecio inaequidens. - Mol. Ecol. 19: 3952-3967.

Legendre, L. and Legendre, L. 1998. Numerical ecology. Developments in environmental modelling. - Elsevier Science and Technology.

Leung, B. et al. 2012. TEASIng apart alien species risk assessments: a framework for best practices. - Ecol. Lett. 15: 1475-1493.

Lobo, J. M. et al. 2010. The uncertain nature of absences and their importance in species distribution modelling. - Ecography 33: 103-114.

Lockwood, J. L. et al. 2005. The role of propagule pressure in explaining species invasions. - Trends Ecol. Evol. 20: 223-228.

Logan, J. A. and Bentz, B. J. 1999. Model analysis of mountain pine beetle (Coleoptera: Scolytidae) seasonality. - Environ. Entomol. 28: 924-934.

Manly, B. F. 2006. Randomization, bootstrap and Monte Carlo methods in biology. - CRC Press.

Maroja, L. S. et al. 2007. Phylogeography of spruce beetles (Dendroctonus rufipennis Kirby) (Curculionidae: Scolytinae) in North America. - Mol. Ecol. 16: 2560-2573.

Marske, K. A. et al. 2013. Phylogeography: spanning the ecology-evolution continuum. - Ecography 36: 1169-1181.

Martínez-Meyer, E. et al. 2004. Ecological niches as stable distributional constraints on mammal species, with implications for Pleistocene extinctions and climate change projections for biodiversity. - Global Ecol. Biogeogr. 13: 305-314.

Michalak, P. et al. 2001. Genetic evidence for adaptation-driven incipient speciation of Drosophila melanogaster along a microclimatic contrast in "Evolution Canyon," Israel. - Proc. Natl Acad. Sci. USA 98: 13195-13200.

Mock, K. E. et al. 2007. Landscape-scale genetic variation in a forest outbreak species, the mountain pine beetle (Dendroctonus ponderosae). - Mol. Ecol. 16: 553-568.

Pearman, P. B. et al. 2010. Within-taxon niche structure: niche conservatism, divergence and predicted effects of climate change. - Ecography 33: 990-1003.

Pearson, R. G. et al. 2004. Modelling species distributions in Britain: a hierarchical integration of climate and land-cover data. - Ecography 27: 285-298.

Pearson, R. G. et al. 2007. Predicting species distributions from small numbers of occurrence records: a test case using cryptic geckos in Madagascar. - J. Biogeogr. 34: 102-117.

Peterson, A. T. 2011. Ecological niche conservatism: a time-structured review of evidence. - J. Biogeogr. 38: 817-827. 
Peterson, A. T. and Holt, R. D. 2003. Niche differentiation in Mexican birds: using point occurrences to detect ecological innovation. - Ecol. Lett. 6: 774-782.

Peterson, A. T. and Nakazawa, Y. 2008. Environmental data sets matter in ecological niche modelling: an example with Solenopsis invicta and Solenopsis richteri. - Global Ecol. Biogeogr. 17: 135-144.

Peterson, A. T. et al. 1999. Conservatism of ecological niches in evolutionary time. - Science 285: 1265-1267.

Petitpierre, B. et al. 2012. Climatic niche shifts are rare among terrestrial plant invaders. - Science 335: 1344-1348.

Phillips, S. J. et al. 2006. Maximum entropy modeling of species geographic distributions. - Ecol. Model. 190: 231-259.

Pimentel, D. et al. 2001. Economic and environmental threats of alien plant, animal, and microbe invasions. - Agric. Ecosyst. Environ. 84: 1-20.

Pimentel, D. et al. 2005. Update on the environmental and economic costs associated with alien-invasive species in the United States. - Ecol. Econ. 52: 273-288.

Rehfeldt, G. E. et al. 1999. Genetic responses to climate in Pinus contorta: niche breadth, climate change, and reforestation. - Ecol. Monogr. 69: 375-407.

Rey, O. et al. 2012. Where do adaptive shifts occur during invasion? A multidisciplinary approach to unravelling cold adaptation in a tropical ant species invading the Mediterranean area. - Ecol. Lett. 15: 1266-1275.

Ridgeway, G. and Ridgeway, M. G. 2004. The gbm package. - R Foundation for Statistical Computing, Vienna, Austria.

Rissler, L. J. et al. 2006. Phylogeographic lineages and species comparisons in conservation analyses: a case study of California herpetofauna. - Am. Nat. 167: 655-666.

Rivera, P. C. et al. 2011. Species delimitation in the continental forms of the genus Epicrates (Serpentes, Boidae) integrating phylogenetics and environmental niche models. - PLoS One 6: e22199.

Rödder, D. and Lötters, S. 2009. Niche shift versus niche conservatism? Climatic characteristics of the native and invasive ranges of the Mediterranean house gecko (Hemidactylus turcicus). - Global Ecol. Biogeogr. 18: 674-687.

Rossi, J.-P. and Blanchart, E. 2005. Seasonal and land-use induced variations of soil macrofauna composition in the Western Ghats, southern India. - Soil Biol. Biochem. 37: 1093-1104.

Ruiz, E. A. et al. 2010. Historical demography and phylogeography of a specialist bark beetle, Dendroctonus pseudotsugae Hopkins (Curculionidae: Scolytinae). - Environ. Entomol. 39: 1685-1697.

Sánchez-Sánchez, H. et al. 2012. Phylogeography reveals routes of colonization of the bark beetle Dendroctonus approximatus Dietz in Mexico. - J. Hered. 103: 638-650.

Savolainen, O. et al. 2007. Gene flow and local adaptation in trees. - Annu. Rev. Ecol. Evol. Syst. 38: 595-619.

Supplementary material (Appendix ECOG-01474 at <www. ecography.org/appendix/ecog-01474>). Appendix 1-2.
Schoener, T. W. 1968. Sizes of feeding territories among birds. - Ecology 49: 123-141.

Schulte, U. et al. 2012. Cryptic niche conservatism among evolutionary lineages of an invasive lizard. - Global Ecol. Biogeogr. 21: 198-211.

Six, D. L. 2012. Ecological and evolutionary determinants of bark beetle-fungus symbioses. - Insects 3: 339-366.

Six, D. L. and Bracewell, R. 2015. Dendroctonus. - In: Hofstetter, F. E. V. a. R. W. (ed.), Bark beetles: biology and ecology of native and invasive species. Academic Press, pp. 305-350.

Strubbe, D. et al. 2013. Niche conservatism in non-native birds in Europe: niche unfilling rather than niche expansion. - Global Ecol. Biogeogr. 22: 962-970.

Strubbe, D. et al. 2015. Invasion success of a global avian invader is explained by within-taxon niche structure and association with humans in the native range. - Divers. Distrib. 21: 675-685.

Sun, J. et al. 2013. Red turpentine beetle: innocuous native becomes invasive tree killer in China. - Annu. Rev. Entomol. 58: 293-311.

Thompson, G. D. et al. 2011. Predicting the subspecific identity of invasive species using distribution models: Acacia saligna as an example. - Divers. Distrib. 17: 1001-1014.

Ungerer, M. J. et al. 1999. Climate and the northern distribution limits of Dendroctonus frontalis Zimmermann (Coleoptera: Scolytidae). - J. Biogeogr. 26: 1133-1145.

VanDerWal, J. et al. 2009. Selecting pseudo-absence data for presence-only distribution modeling: how far should you stray from what you know? - Ecol. Model. 220: 589-594.

Warren, D. L. et al. 2008. Environmental niche equivalency versus conservatism: quantitative approaches to niche evolution. - Evolution 62: 2868-2883.

Warren, D. L. et al. 2014. Mistaking geography for biology: inferring processes from species distributions. - Trends Ecol. Evol. 29: 572-580.

Webber, B. L. et al. 2011. Modelling horses for novel climate courses: insights from projecting potential distributions of native and alien Australian acacias with correlative and mechanistic models. - Divers. Distrib. 17: 978-1000.

Wisz, M. S. et al. 2008. Effects of sample size on the performance of species distribution models. - Divers. Distrib. 14: 763-773.

Wood, S. L. 1963. A revision of the bark beetle genus Dendroctonus Erichson (Coleoptera: Scolytidae). - West. N. Am. Nat. 23: $1-116$.

Wood, S. L. 1982. The bark and ambrosia beetles of North and Central America (Coleoptera: Scolytidae), a taxonomic monograph. - Gt Basin Nat. Mem. 6: 1-625.

Yan, Z. et al. 2005. The red turpentine beetle, Dendroctonus valens LeConte (Scolytidae): an exotic invasive pest of pine in China. - Biodivers. Conserv. 14: 1735-1760. 